\title{
$\mathrm{CAE}$ 를 이용한 이중사출 제품의 러너 및 게이트 영향에 대한 연구
}

김옥래" ${ }^{*}$ 차백순 ${ }^{1}$ 이상용 ${ }^{1} \cdot$ 김영근 $^{1} \cdot$ 우창기 $^{2}$

\section{A Study on the Runner and Gate Consequence of Manufacture Double Shot Molding using CAE}

\author{
O. R. Kim, B. S. Cha, S. Y. Lee, Y. G. Kim, C. K. Woo
}

(Received February 26, 2009)

\begin{abstract}
A Study on Effects of the Runner and the Gate of double shot injection molded Parts using CAE

Double shot injection molding can inject two different materials or two different colors in the same mold in a injection molding process. Double shot injection molded parts can be characterized that the base part maintains strength and specified part can inject soft-material. It can reduce the production cost by single automatic operations. In this paper, we designed double shot injection mold for automobile remote control To inject secondary part, this part is used as an insert after external appearance of product is injected. CAE analysis was progressed gate location and runner size as variables. The analysis result is reflected in mold design process. As a result, it could solve problems which are generated in the conventional mold. Additionally, cost can be downed by reducing runner weight. As well as it could omit painting process because the surface of finished product is improved through new mold.
\end{abstract}

Key Words : Injection Molding, Mold Design, Flow Analysis, Warpage, Deflection, Double Shot Injection

\section{1. 서 론}

최근 원가상승으로 인하여 철에서 플라스틱 소 재로 변경하려는 시도가 활발하게 이뤼지고 있으 며, 플라스틱은 일반 생활가전(용기, TV)에서 자동 차 엔진부품 등의 첨단 산업분야에 이르기 까지 다양하게 적용되고 있다. 이중사출은 이종 혹은 색이 다른 동일 플라스틱 재료를 조합하여 제품 미관 및 내열, 내후, 내강도, 밀폐둥의 기계적 톡 성을 높이기 위한 성형공법으로 널리 사용되고 있다. 이중사출의 공법은 1 차성형 후 금형이 체 결되어 있는 회전판을 회전시켜서 2 차 성형을 하
는 방식, 코어핀을 이용하여 코어를 회전시키는 방식, 로봇을 이용하여 1 차 성형품을 2 차 성형 금형으로 이동시켜 성형하는 방식, 1 차 성형품을 금형 내 슬라이드 코어를 이용하여 2 차 측으로 이동시켜 성형하는 방식(Die Slide Injection Molding) 등이 있다.

최근 금형은 복잡하고 다양한 시스템 구조로 변해가며 복합적인 생산시스템으로 변해가면서 다양한 연구가 진행되고 있다. Lee 와 $\mathrm{Kim}$ 은 사출 성형품의 휨을 제어할 수 있는 최적화 기법을 제 시 하였으며[1], Huang 과 Tai 는 얇은 셀 구조물 변형의 영향인자 평가를 하였다[2]. 그러나 이들의

\footnotetext{
1. 한국생산기술연구원 금형기술지원센터

2. 인천대학교 기계공학과

\# 교산저자: 금형기술지원센터(인천대학교 기계공학과),

E-mail:kor@kitech.re.kr
} 
연구는 일반 사출성형에 국한된 연구이며, 이중 사출에 관한 성형인자 평가에 관한 국내 연구는 미비한 실정이다.

본 연구는 1 차 폴리아미드(nylons,PA66), 2 차 우 레탄(TPU) 재료를 사출하는 이중사출 제품에 대 해서 성형품 변형량에 영항을 미치는 인자를 알 아보았다. 기존 연구에서는 성형조건 및 냉각에 따른 변형량 개선 방안을 연구하였다면[3], 본 연 구에서는 사출성형품의 게이트 및 러너 크기가 변형량에 미치는 영향에 관하여 다루도록 하였다. 이를 위해서 해석을 통한 각 조건별 성형 압력을 비교하였으며, 도출된 성형압력 및 변형량을 최소 화하는 조건을 금형제작에 반영하도록 하였다. 또 한 최적 사출 공정의 확립을 위하여 실험결과와 해석을 비표하도록 하였다.

\section{2. 제품 특성 분석}

본 연구에서는 자동차용 리모콘 제품을 대상으 로 하였으며 Fig. 1에 나타내고 있다.

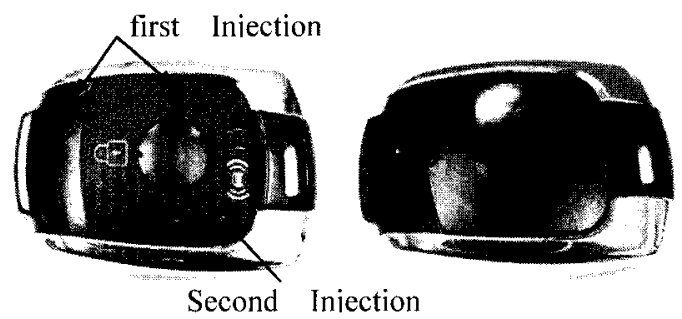

Fig. 1 Photo of automotive remote control

1차 성형품의 재료는 폴리아미드(nylons, PA66) 로써, GF(Glass Fiber) 15\%와 Mineral 25\% 를 함유 하고 있다. 따라서 사출온도는290 $295^{\circ} \mathrm{C}$, 금형온 도는 $25 \sim 95^{\circ} \mathrm{C}$ 를 가지는 특징이 있다. 2 차 성형품의 재료는 제품 사용자의 촉감 및 성능 문제로 엘라 스토머(TPU)를 사용하며, 사출온도는 $245 ~ 260{ }^{\circ} \mathrm{C}$, 금헝온도는 $38 \sim 110^{\circ} \mathrm{C}$ 를 가지는 특징을 가지고 있 다. 리모컨 제품 특성상 표면에 결함을 주는 웰드 라인, 유동자국, 타버림 등의 성형 불량이 있어서 는 안되며, 또한 리모콘 제품의 조립의 문제로 변 형, 휨 등으로부터 치수적 안정성이 확보되어야 하는 톡징을 가지고 있다. 특히 게이트와 러너의 크기 및 위치에 따라 유동 패턴(충전성) 및 웰드 라인의 차이가 발생하고 변형에도 영향을 미치는 복합적인 요소를 가지고 있는 제품이다.

\section{3. 사출성형해석}

\section{1 해석조건선정}

$\mathrm{CAE}$ 해석에서 금형의 설계변수와 사출성형 조 건을 모두 고려한 최적의 사출성형 조건을 도출 해야 하며, 이를 위해서는 많은 시간과 노력이 소 요된다. 따라서 설계공정을 체계적으로 예측하여 제품성능, 비용 및 외관에 영향을 미치는 공정변 수의 효과에 관한 정보를 얻기 위한 방법으로 사 출성형해석을 활용하고 있다[4].

본 연구의 목적인 게이트 및 러너 크기에 따 른 성형품의 변형을 알아보기 위하여 몰드플로 우를 사용하여 사출성형해석을 수행하였으며, 사 용된 수지의 물성 및 성형조건을 Table 1 에 나타 내었다.

보압의 경우는 70-30Mpa 로 설정하여 해석을 수 행 했으며 Fig. 2 에 1 차, 2 차 성형에 사용된 보압 조건을 나타내고 있다.

Table 1 Condition of CAE analysis

\begin{tabular}{c|c|c}
\hline & 1st (PA66) & 2nd (TPU) \\
\hline Manufacture & Delphi & Noveon \\
\hline Grade & DE105 & CM3995 \\
\hline Injection time & Automatic & Automatic \\
\hline Cooling time & $8 \mathrm{sec}$ & $6 \mathrm{sec}$ \\
\hline Melt temp. & $292^{\circ} \mathrm{C}$ & $253^{\circ} \mathrm{C}$ \\
\hline Mold temp. & $80^{\circ} \mathrm{C}$ & $60^{\circ} \mathrm{C}$ \\
\hline Packing time & $3 \mathrm{sec}$ & $3 \mathrm{sec}$ \\
\hline
\end{tabular}

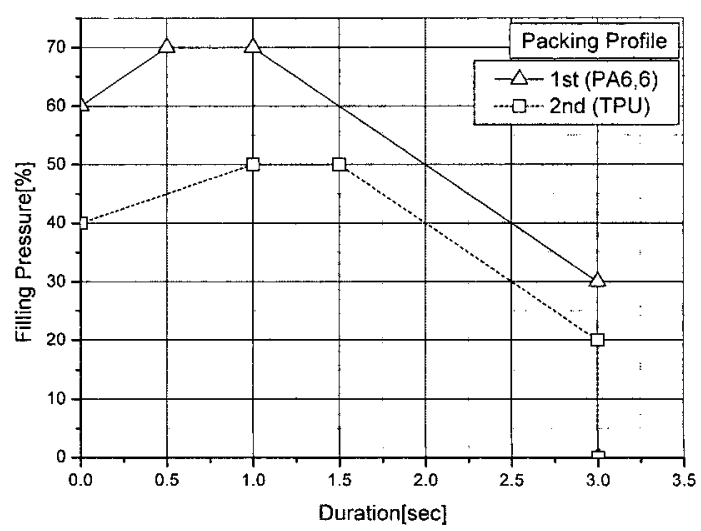

Fig. 2 Packing pressure profile of PA6,6 \& TPU 

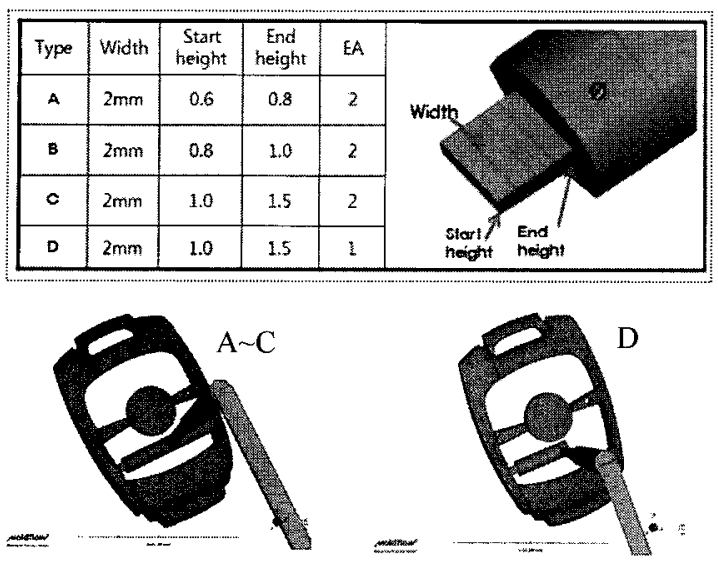

Fig. 3 Set of design parameter on $1^{\text {st }}$ molded part

\begin{tabular}{|c|c|c|c|c|}
\hline & A & B & C & D \\
\hline Size & $\emptyset 3$ & $\emptyset 4$ & $\emptyset 3$ & $\emptyset 4$ \\
\hline Type & Half & Half & Circle & Circle \\
\hline
\end{tabular}
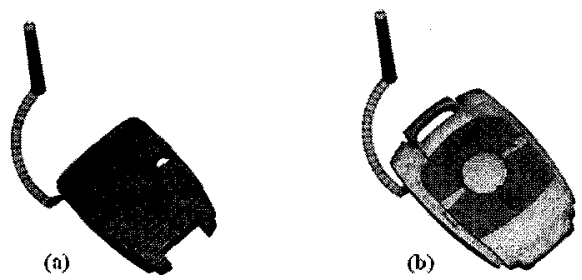

Fig. 4 Set of design parameter on $2^{\text {nd }}$ molded part

\subsection{1 차, 2차 주요 성형 인자 선정}

본 제품의 경우 게이트의 치수를 일정하게 유 지하고 러너의 크기 조정을 통한 유동성 및 밸런 스가 확보되어야 하지만, 1 차 성형품의 경우 러너 의 크기를 변경할 수 없는 금형 구조적 제약을 가지고 있다. 따라서 1 차 성형품의 경우 게이트 치수를 변화하였으며, 2 차 성형품의 경우 러너 크 기에 따른 사출충전속도 및 보압조건을 도출하여 진행하였다.

Fig. 3 에는 해석에 사용된 1 차 성형품과 조건별 게이트 치수를 나타내고 있으며, D 조건의 경우는 편측 게이트를 적용하였다.

2 차 성형품의 경우는 사출압력, 온도 분포, 충 전시간, 변형량 등을 고려하여 러너의 크기를 최 적화 하도록 하였다. 이는 재료의 절감과 사출성 형 중의 냉각 시간 절감을 통한 에너지 소비 효 율을 높이기 위함이다. Fig. 4 (a)에 2 차 성형품의 형상을, (b)에는 1 차성형품을 인서트 시켰을 때의

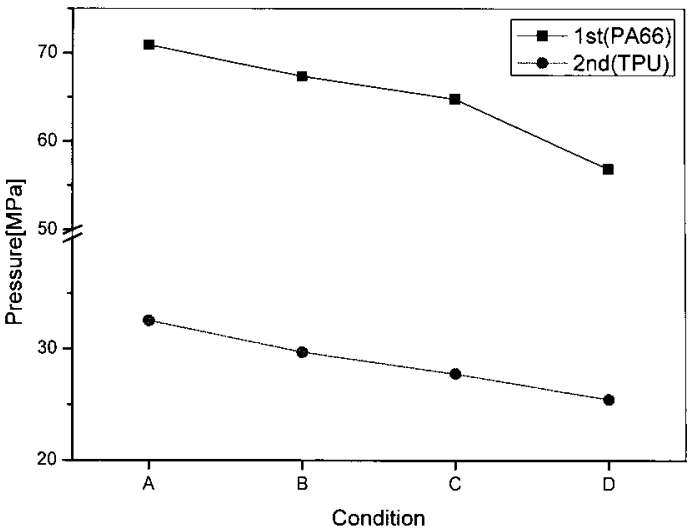

Fig. 5 The result of injection pressure packing pressure

형상을 보여주고 있으며, 각각의 해석 조건을 나 타내고 있다.

\subsection{1차, 2차 성형 해석 결과}

Fig. 5 에는 1 차, 2 차 성형품의 조건별 사출압력 결과를 나타내고 있다.

1 차 성형품의 게이트 크기별 결과를 살펴보면, 게이트가 작은 $\mathrm{A}$ 의 경우는 압력이 $70.9 \mathrm{Mpa}$ 로 높 게 형성되었으며, 게이트 크기가 커질수록 압력이 낮아짐을 확인할 수 있었다. 특히 $\mathrm{D}$ 의 경우 게이 트 1 점을 사용하지만 가장 낮은 압력인 $56.89 \mathrm{Mpa}$ 를 보였다. 이는 $\mathrm{A} \sim \mathrm{C}$ 조건의 경우 2 점 게이트를 사용함으로 인하여 수지의 유동이 서로 분기되어 충전 중에 분기된 수지가 만나며, 과보압을 형성 하게 되어 높은 압력이 나타난 것으로 보인다. 그 러나 $\mathrm{D}$ 조건과 같이 1 점 게이트를 사용하였을 경 우는 과보압의 형성 없이 원활한 충전이 이뤄졌 기 때문에 상대적으로 낮은 압력을 가지는 것으 로 보인다.

Fig. 6 에는 각 조건별 유동 패턴 결과를 나타내 고 있으며, 제품 외관에 영향을 미치는 웰드라인 의 분포가 $\mathrm{A} \sim \mathrm{C}$ 의 경우 외관에 영향을 미치는 부 위에 형성됨을 알 수 있다. 그러나 $\mathrm{D}$ 의 경우는 웰드라인이 제품 외곽부로 분포되어 외관에 큰 영향을 미치지 않음을 확인할 수 있다.

2 차 성형품의 경우는 유동성이 좋은 TPU 를 사 용하기 때문에 사출압력의 경우 1 차 성형품과 다 르게 낮게 분포됨을 확인 할 수 있다.

러너 크기에 따른 사출압력의 분포를 살펴 보 면 $25.5 \sim 32.5 \mathrm{MPa}$ 를 형성하고 있으며, 러너의 크 기가 가장 큰 $\mathrm{D}$ 조건이 사출압력이 가장 낮게 형 


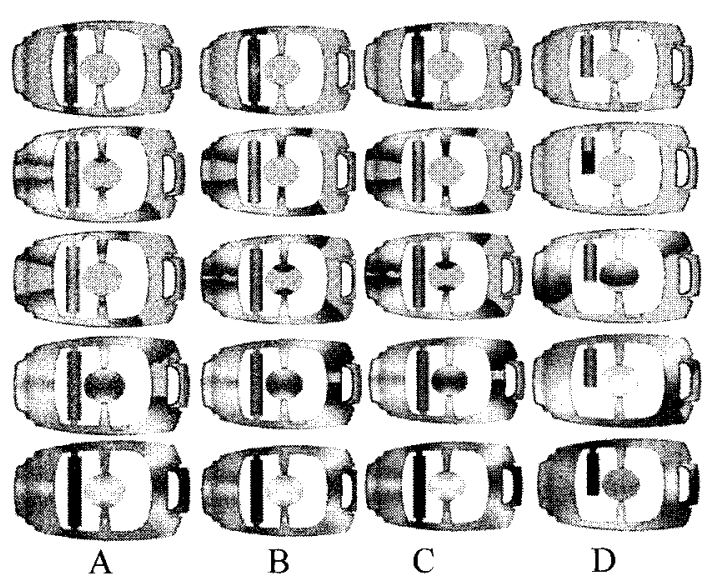

Fig. 6 The flow pattern of $1^{\text {st }}$ molded part

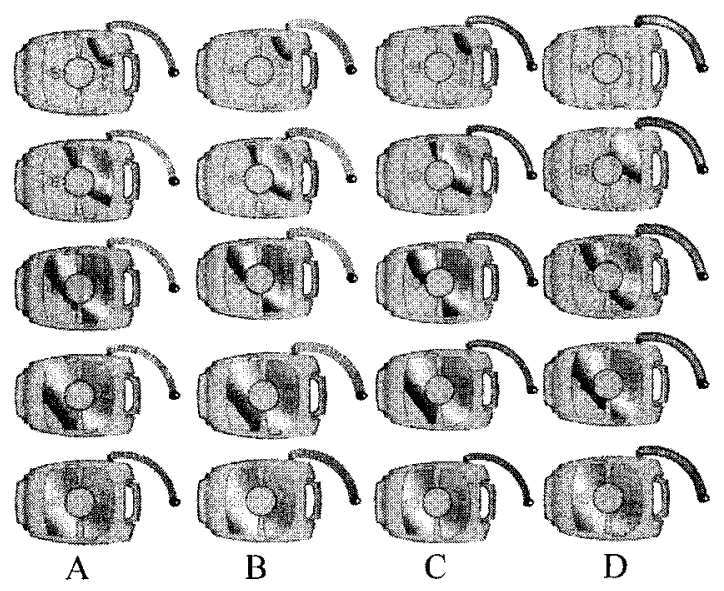

Fig. 7 The flow pattern of $2^{\text {nd }}$ molded part

성되었다. 그러나 2 차 성형품의 경우 압력의 분 포가 전체적으로 낮게 형성되고, 웰드라인의 분포 또한 각 조건이 유사한 분포를 가지고 있기 때문 에 재료의 절감과 사출성형 중의 냉각 시간 절감 을 고려하였을 때 $\mathrm{A}$ 조건을 최적 조건으로 판단 하였다. Fig. 7 에는 2 차 성형품의 유동 패턴을 보 여주고 있다.

Fig. 8 에는 1 차, 2 차 성형품의 조건별 변형량을 나타내고 있다. 1 차 성형품은 $0.03 \mathrm{~mm} 0.05 \mathrm{~mm}$ 로 나타나고 있으며, 2 차 성형품의 경우는 $0.18 \mathrm{~mm}$ $0.22 \mathrm{~mm}$ 로 1 차 성형품에 비해서 높은 변형량을 보이고 있다. 이는 1 차 성형품의 높은 열이 2 차 성형품의 변형에 추가적으로 영향을 미치기 때문 으로 판단된다. 그러나 2 차 성형품의 변형량의 분포가 설계 사양에 모두 만족하기 때문에 본 연

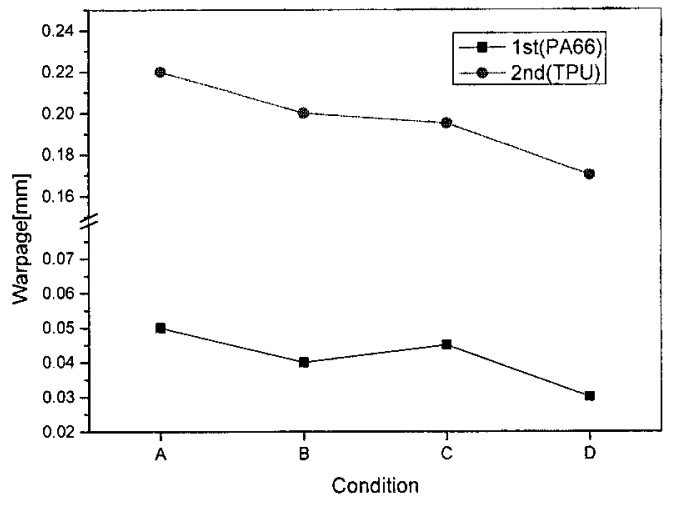

Fig. 8 The result of warpage according to CAE conditions

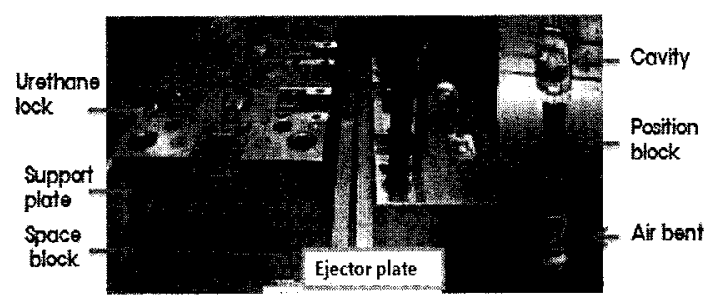

(a) 1 st Mold

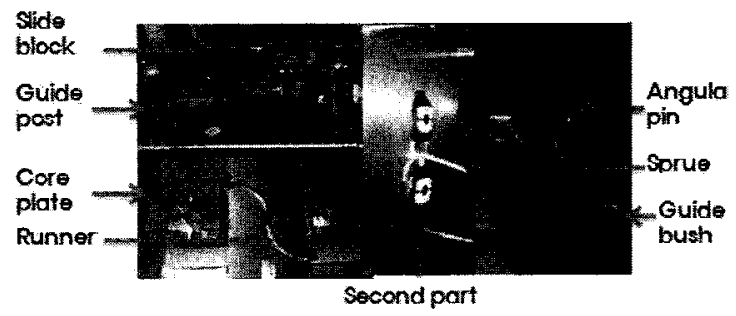

(b) 2nd Mold

Fig. 9 Photo of manufactured $1^{\text {st }} \& 2^{\text {nd }}$ mold

구에서는 $\mathrm{A}$ 조건을 설계에 적용하도록 하였다.

\section{4. 사출성형실험}

$\mathrm{CAE}$ 해석을 통하여 최종적으로 선택된 게이트 및 러너를 적용한 자동차용 리모콘 생산을 위한 1 차, 2 차 사출 금형을 Fig. 9 에 나타내고 있다.

사출성형 실험에는 110 톤 우진세렉스 사출기를 사용하였으며, 성형조건의 경우는 Table 1 에 제시 된 성형 인자와 수준으로 진행하였다[5]. 특히, 재 료의 수분 흡수로 인한 변형량의 영향을 제거하 기 위하여, 제습식 건조기에서 $90^{\circ} \mathrm{C}$ 로 6 시간의 건조 과정을 거치도록 하였다.

또한 성형기의 재연성을 고려하여 각 조건별로 


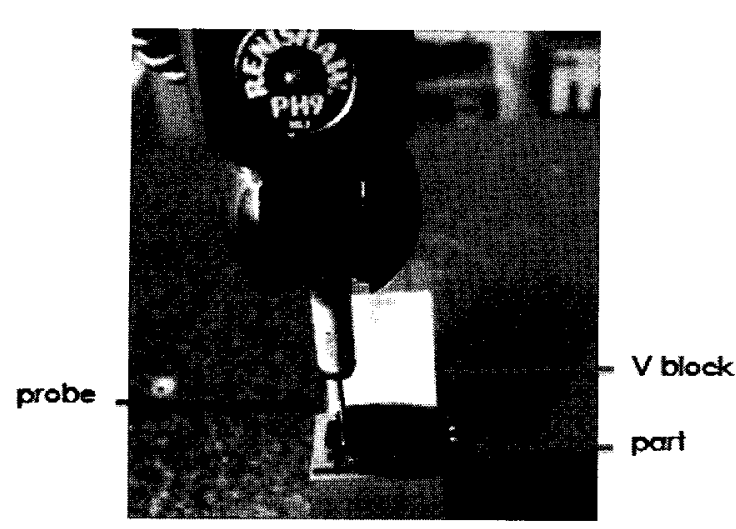

Fig.10 Warpage measurement of molded part using CMM

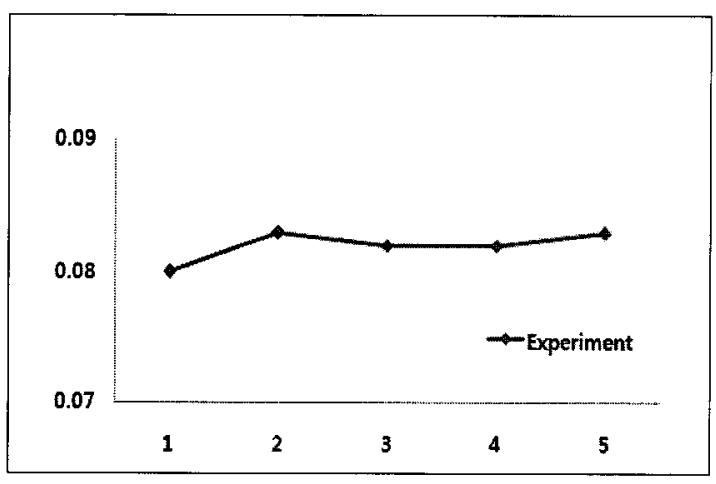

Fig.11 Distribution of warpage of molded part

5 개의 제품을 사출한 후 제품 특성상 가장 평탄 도가 높은 부위 3 점을 기준으로 평면을 유지시킨 뒤에 변형값을 측정하였다. 또한 성형품의 잔류 변형을 고려하여 취출된 사출성형품은 48 시간이 지난 후에 성형품의 평면도(휨)를 측정하도록 하 였다. Fig. 10 에는 측정에 사용된 3 차원 측정기 (CMM)를 나타내고 있다.

촉정값은 Fig. 11 과 같이 $0.08 \mathrm{~mm} \sim 0.083 \mathrm{~mm}$ 로 측 정이 되었다. 이는 1 차 성형된 제품에 2 차성형 할 때의 인서트물이 플라스틱 제품이고, 1 차 성형 품의 성형 후 잔류 온도가 2 차 성형품의 냉각 중 에 일어나는 성형수축에 영향을 미쳐 2 차 변형을 유발하는 것으로 판단된다. 그러나 2 차 성형품의 유동해석 변형량 분포 보다 실험 결과물의 측정 값이 양호한 변형량을 보여주고 있으며, 균일하고 안정된 치수의 오차를 나타내고 있음을 확인할 수 있다.

\section{5. 결 론}

본 연구에서는 폴라스틱 제품 개발에서 시행착 오를 최소화하며, 사출 성형의 과정에서 생산성과 품질 향상을 위해 과학적이고 합리적인 접근을 하기 위해 사출성형해석을 활용하였다. 사출성형 해석과 실험결과를 고찰 및 분석함으로써, 이중사 출의 서로 다른 이종재질간의 대표적 성형불량 중 하나인 변형 최소화를 위한 금형설계 데이터 를 확보하고, 최적 사출성형 조건을 도출하였다. 본 연구를 통하여 다음과 같은 결과를 얻을 수 있었다.

(1) $\mathrm{CAE}$ 해석을 수행한 1차 제품에서는 게이트의 크기가 작을수록 압력이 높아지고 충전속도가 매 우 빠르게 나타넜으며, 성형품의 면형량에 영향을 미치는 것으로 나타났다.

(2) 1 차 제품에서는 게이트의 수가 많은 것 보다 적을 때 웰드라인, 에어트랩, 변형 등이 비교적 좋게 나타나고 있다.

(3) 2차 성형해석에서는 유동성이 좋은 TPU의 사용으로 인하여, 러너의 크기에 대한 영향이 적 게 나타나고 있다.

(4) 2차 성형해석에서는 1차 제품 위에 2차 성형 되기 때문에, 1 차 플라스틱 제품의 높은 열로 인 하여 2차 제품의 냉각에 영향을 미침을 변형량 분포의 분석을 통하여 확인할 수 있었다.

(5) 사출성형 실험을 통하여 해석에서 도출된 변형 패턴이 실험 결과와 유사한 경향을 보이며, 측정값이 균일하고 안정된 치수 오차 분포를 나 타내었다.

\section{후 기}

본 연구는 “자동차용 REMOCON 제품의 생산성 향상을 위한 이중사출 금형설계 기술 지원” 및 "미니 노트북용 대면적 투명 이중사출 몰드 프레 임 생산기술 지원” 과제의 지원으로 진행되었으며, 이에 감사드립니다.

\section{참 고 문 헌}

[1] B. H. Lee, B. H. Kim, 1997, Variation of Part Wall Thicknesses to Reduce Warpage of Injection Molded Part-Robust Design Against Process Variability, Polymer Plastics Technology \& 
Engineering Journal, Vol.36, No.5, pp. 791 807.

[2] M. C. Huang, C. C. Tai, 2001, The effective factors in the warpage problems of an injected-molded part with a thin shell feature, Journal of Materials Processing Technology, Vol.110, pp. 1 9.

[3] S. H. Lee, C. J. Hwang, O. R. Kim, Y. M. Heo, 2004, The Warpage of Orthogonal Stiffened Structures in Injection Molding, PPS Asia/Australia meeting, pp.
45 46.

[4] O. R. Kim, M.Y. Kim, S. H. Lee, C. O. Kwon,2006, A Study on Plastic Injection Molding for Warpage Characteristics Evaluation of Mobile Phone Cover, Transactions of Materials Processing, Vol.15, No.1, pp. 76 81.

[5] S. H. Park, 1998, Hyun Dai design of experiments, Min Young Sa. 